\title{
Product attributes affecting consumer preference for residential deck materials
}

\author{
Anders Q. Nyrud, Anders Roos, and Marit Rødbotten
}

\begin{abstract}
In many countries, restrictions on the use of traditional preservative treatments have resulted in efforts to develop wood products for outdoor use that are durable, environmentally friendly, and appealing to consumers. In the present study, consumers' preferences for wooden deck materials were investigated using sensory analysis. The analysis included an analytical sensory profiling of five deck materials, conducted by a trained sensory panel, as well as a hedonic preference study conducted on Norwegian customers. Eighteen visual and tactile attributes were identified, and statistical analysis indicated that these attributes were sufficient to discriminate between the different deck materials. The results imply that consumers prefer deck materials with a homogeneous visual appearance and moderate color intensity. The study demonstrated a successful application of sensory research on wood products and implies that sensory analysis is an appropriate tool to study relationships between hedonic judgments and product characteristics. The study was carried out on wooden deck materials, but the results are probably also relevant for other wood products.

Résumé : Dans plusieurs pays, les restrictions concernant l'utilisation des traitements traditionnels avec des préservatifs ont suscité des efforts pour développer des produits du bois destinés à être utilisés à l'extérieur qui sont durables, respectueux de l'environnement et attrayants pour les consommateurs. Dans cette recherche, nous avons étudié les préférences des consommateurs pour les matériaux de terrasse en bois à l'aide de l'analyse sensorielle. L'analyse incluait l'établissement du profile sensoriel de cinq matériaux de terrasse, réalisé par un jury entraîné à cette fin, ainsi qu'une étude hédonique de préférence réalisée par des consommateurs norvégiens. Dix-huit attributs visuels et tactiles étaient suffisants pour distinguer les différents matériaux de terrasse. Les résultats suggèrent que les consommateurs préfèrent les matériaux de terrasse qui ont une apparence visuelle homogène et une coloration de moyenne intensité. L'étude constitue une démonstration de l'application réussie de la recherche sensorielle à des produits du bois et indique que l'analyse sensorielle est un outil approprié pour étudier la relation entre les jugements hédoniques et les caractéristiques d'un produit. L'étude a porté sur les matériaux de terrasse en bois mais les résultats sont probablement également pertinents pour d'autres produits du bois.
\end{abstract}

[Traduit par la Rédaction]

\section{Introduction}

Wood used in the outdoor environment is subject to biological decay. To improve product life, wood is treated with chemical preservatives or modified mechanically. Preservative-treated wood is often used in private gardens as well as in parks, for example, home owners build outdoor decks to expand living space and connect the home with the outdoors; over $6.5 \times 10^{6}$ residential decks were estimated as having been constructed in the United States (cf. Smith and Sinclair 1989; Shook and Eastin 2001; Fell et al. 2006). In western Europe, $21 \%$ of the total production of preservative-treated wood is used by home owners in gardens (Western European Institute for Wood Preservation 2006). The Timber Decking Association in the United
Kingdom reported that the United Kingdom market for timber decks doubled from $£ 60$ million in 2000 to $£ 120$ million in 2004 and anticipated a further increase (Timber Decking Association 2005). The United Kingdom Forestry Commission has attributed the increased demand for wooden decks and garden furniture to presentations in magazines and television programs (United Kingdom Forestry Commission 2004, 2005).

In North America and Europe, chemical preservatives such as chromated copper arsenate (CCA) and creosote (a petroleum-based preservative) have been widely used until recently. If exposed to water (for example, through rain), both treatments can leach toxic chemicals to the environment (Townsend et al. 2003; Lebow et al. 2004). Concerns about the potential toxicity of chemically treated wood have

Received 23 January 2006. Resubmitted 2 May 2007. Accepted 2 October 2007. Published on the NRC Research Press Web site at cjfr.nrc.ca on 3 May 2008.

A.Q. Nyrud. ${ }^{1}$ Department of Ecology and Natural Resources Management, Norwegian University of Life Sciences, P.O. Box 5003, NO-1432 Ås, Norway.

A. Roos. Department of Ecology and Natural Resources Management, Norwegian University of Life Sciences, P.O. Box 5003,

NO-1432 As, Norway; Department of Forest Products and Markets, Swedish University of Agricultural Sciences, P.O. Box 7060 , S-750 07 Uppsala, Sweden.

M. Rødbotten. Norwegian Food Research Institute, Osloveien 1, NO-1430 Ås, Norway; Department of Chemistry, Biotechnology and Food Science, Norwegian University of Life Sciences, NO-1430 Ås, Norway.

${ }^{1}$ Corresponding author (e-mail: anders.q.nyrud@ treteknisk.no). 
led to attempts to phase out such products in several countries. As early as 2001, CCA-treated products were withdrawn from the Canadian market because of health concerns (Fell et al. 2006), and a similar restriction on CCA-treated wood was imposed in 2003 by the Australian Pesticides and Veterinary Medicines Authority (2005a, 2005b). In 2003, the United States Environmental Protection Agency and the wood-products industry agreed to phase out CCA for nonindustrial uses (Office of the Federal Register 2003; United States Environmental Protection Agency 2005). In Europe too, concerns about toxic emissions from treated wood have resulted in new legislation. The European Union issued a directive restricting sale and use of preservatives containing arsenate in 2004 (European Commission 2003). The Norwegian Ministry of the Environment banned CCA and creosote preservatives in 2002 (Jacobsen and Evans 2002). However, CCA is allowed to be used in industrial installations and structures in cases where durable materials are necessary for public safety.

Because of the new restrictions on preservatives, new and environmentally friendly wood preservation technologies are receiving increased interest from consumers, policy makers, and the forest and chemical industries. The forest and chemical industries are currently developing preservatives and preservative treatment methods that are environmentally sound, accepted by the public, and competitive with respect to price, durability, and aesthetic properties. For example, pressure-treated wood where water-borne metals are substituted with organic biocides are now commercially available, and the demand for naturally decay-resistant wood is increasing in many countries. New technologies for wood modification have also been developed, such as wood-plastic composites, heat treatment, acetylation, ${ }^{2}$ furfurylation, ${ }^{3}$ and treatments using resins and wax. Product development has mainly focused on developing preservatives and modification technologies that enhance durability. There is in general little knowledge about consumers' tastes for, and attitudes toward, product attributes and their willingness to pay for decay-resistant wood products.

Detailed knowledge of consumers' functional and aesthetic requirements can provide competitive advantages for the forest industry, and this will improve consumer satisfaction if the information is used to develop new products in accordance with consumers' tastes. Evans and Smith (1968) emphasized in an early article on wood-product attributes that it is of substantial importance to identify (forest) product attributes that are desired by consumers so that the firm can deliver a product that meets consumer expectations. There is still little knowledge about salient forest products attributes and how these affect customer preferences. Therefore, efforts should not only be concentrated on developing elicitation techniques for identifying product attributes, but also on developing methods to analyze and model consumer preferences.

A comprehensive review of attribute research in forest products is provided by Brandt and Shook (2005). They con- cluded that product attributes have an impact on consumers' preferences for wood products. These attributes include physical (tactile and visual) attributes and intangible attributes, such as service and environmental impact. Brandt and Shook (2005) also noted that there is a need for proven elicitation methodologies in forest research, and therefore, there is a need to evaluate different ones. They also pointed out that no studies have provided clear evidence of internal and external consistency in the attributes chosen for a study and that there are very few attribute analyses carried out within the domain of forest products that have focused on consumer markets.

In addition to the articles reviewed by Brandt and Shook (2005), there are a few studies that have concentrated on forest products attributes and consumer preferences. Marchal and Mothe (1994) studied preferences for oak wood among professional and nonprofessional wood users and found that the most important factors for wood appreciation were knottiness, cut orientation, tint, and annual ring width. Broman (2000) analyzed aesthetic features of wood for interior use (wooden flooring and furniture) and identified a set of key concepts that described a set of respondents' attitudes towards wood products (freshness, harmony, interest, elegance, excitement, restfulness, eventfulness, naturalness, imaginativeness, and absence of gaudiness). Based on these concepts, Broman (2000) concluded that the opinions of his respondents on wooden surfaces were influenced by the perceived activity and harmony of the surface texture. Pakarinen and Asikainen (2001) investigated consumer preferences for kitchen cabinets and identified five main dimensions of choice that were important to consumers: environmental friendliness, price, advertising, quality, and style. Jonsson (2005) compared consumers' preferences for different types of flooring materials. He concluded that aesthetic qualities were important for consumers choosing wooden flooring. Bigsby et al. (2005) studied consumer preference for furniture timber. They presented samples of wood for consumers to consider and found that color and grain were the key timber attributes that consumers use to form their preference.

There are a few studies concentrating on treated wood. Smith and Sinclair $(1989,1990)$ investigated builders' perceptions of treated lumber products and found that the most preferred attributes were straightness, appearance, and grade. This reflects the industry having attained a mature stage with a low degree of differentiation. Reddy and Bush (1998) investigated trade-offs between lumber attributes and price of softwood lumber for preservative treatment. Vlosky and Shupe (2002) studied homeowners' perceptions of building materials and found that homeowners in general have a positive impression of treated wood, although there is a smaller segment who would be reluctant to buy treated wood because of health concerns. This result was also reached in a later study by the same authors (Vlosky and Shupe 2004). They concluded that homebuilders in general are positive towards treated wood, but there is a need for

\footnotetext{
${ }^{2}$ Acetylation of wood is an anhydride modification process that results in the substitution of hydrogen atoms in cell wood hydroxyl groups with acetyl moieties (Goldstein et al. 1969).

${ }^{3}$ Furfurylation of wood is a modification method that involves reaction with furfuryl alcohol under weak acidic conditions at elevated temperatures (Lande et al. 2004).
} 
Fig. 1. Fishbeins' multiattribute attitude model (From Ryan 1986, reproduced by copyright permission of Springer Science and Business Media).

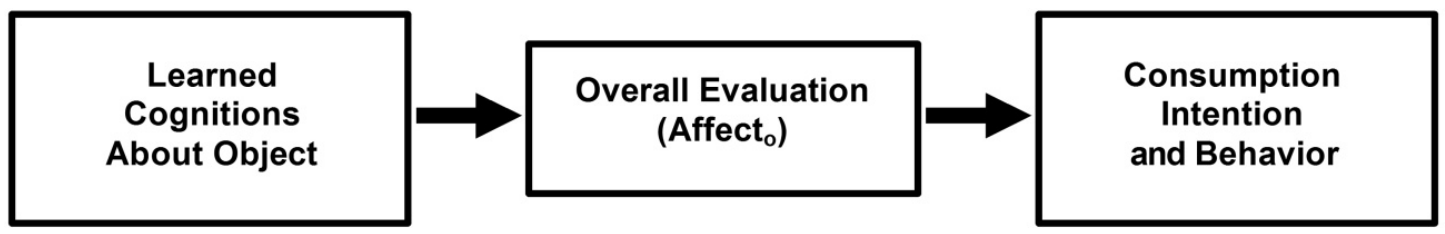

better information about how to handle treated wood products. Donovan and Hesseln (2004) investigated whether recent concerns about the risks of CCA have created market opportunities for playground facilities of naturally decay-resistant wood. They found that consumers are willing to pay a premium for a children's play structure made from nontoxic materials. This result agrees with another study that investigated playground manufacturers' perceptions of treated wood: health criteria are the most important considerations in material choice (Vlosky and Shupe 2005). Consumer perceptions regarding residential deck materials were investigated by Fell et al. (2006). Based on two conjoint studies from 2000 and 2003, they concluded that consumers have become more negative towards treated wood and more positive to wood-plastic composites during the study period.

The goal of this study is to identify and measure attributes of wood that affect consumers' preferences. This is done by means of analytical sensory profiling. Five different wooden deck materials are used in the study. Sensory analysis is a well-established methodology and is in use in several industrial marketing contexts but has not yet been used on wood products. A panel is used to identify and measure product attributes; combined with data from hedonic consumer surveys, the attribute measurements can be used to identify salient product attributes. In the existing literature, there is a lack of research using well-documented and recognized procedures for attribute elicitation, and the results are often difficult to interpret. Brandt and Shook (2005) provided clear evidence of internal and external inconsistency of the attributes chosen in previous research, and the method presented in this study suggests a way to bridge this gap. The results have implications for product development and marketing of modified and preservative-treated wood.

\section{Theory and method}

\section{Consumer behavior models}

Engel et al. (1995) defined consumer behavior as "...those acts of individuals directly involved in obtaining, using and disposing of economic goods and services." Several approaches have been proposed for conducting consumer research. In existing forest research, positivist rational approaches, based on the assumption of individuals maximizing utility, have typically been used to model preferences of consumers who purchase forest products. Traditional consumer behavior theories are frequently based on the assumption that consumers demand characteristics of products rather than specific products. Thus, surveying consumers' attitudes towards a product and identifying which product attributes are salient for the consumers will provide information that can be used to predict consumer choice (Lancaster 1966).

Fishbein (1963) provided a theoretical framework for cog- nitive motivational consumer models through his multiattribute attitude model: behavior, for example, a purchasing decision, is based on the perceived attributes or learned cognitions of a product. Consumer attitude toward a product is influenced by a set of salient product attributes, and the consumer evaluates product attributes in a cognitive process influenced by the customer's intention of consumption (Fig. 1).

Therefore, information about product attributes and attributer saliency can be used to predict consumer behavior. Consumer attitude is the weighted sum of independent attributes or affects:

$$
\text { [1] } \quad A_{\mathrm{o}}=\sum_{i=1}^{n} b_{i} e_{i}
$$

where $A_{\mathrm{o}}$ is the attitude towards an object, $n$ is the number of salient attributes identified $(i=1,2, \ldots, n), b_{i}$ is the strength of belief toward an attribute, and $e_{i}$ is the evaluation of the corresponding attribute (Fishbein 1963). Fishbein's cognitive motivations theory has been further developed, cf. the theory of reasoned action and theory of planned behavior (Ajzen and Fishbein 1977, 1980).

Traditional positivist cognitive models can be elaborated to take into account additional effects influencing the consumer (i.e., effects arising from situations, social influences, or personal feelings), but sufficient constructs must be identified in these cases (Ryan 1986). Recent development in consumer behavior theory includes the so-called nonpositivist, holistic, or interpretive theories. Nonpositivist models combine information about individual and social symbolism and treat consumers as autonomous decision makers who can only be understood from the basis of their present life situation and past experiences (Pachauri 2001).

In this study, a traditional positivist approach is used to analyze the relationship between physical attributes and consumers' preference for five deck materials. Therefore, Fishbeins' multiattribute attitude model is applied in the analysis. First, physical product attributes are identified and measured; subsequently, this information is coupled with information about consumers' attitudes (or likings) and used to model consumer preferences. Applying a traditional, positivist consumer behavior model does not rule out nonpositivist and postmodern methodology in future research; as noted in Pachauri (2001), it is possible to use results from traditional studies later on in nonpositivist consumer models.

\section{Material samples}

Data for the multiattribute attitude model were collected by showing samples of different deck materials to a panel consisting of trained sensory assessors and a group of representative customers. Five deck materials were used in the analysis: (I) naturally decay-resistant tropical wood (ipé, $\mathrm{Ta}$ - 
Table 1. Descriptive information for the sample decks.

\begin{tabular}{llllll}
\hline Sample & Commercial & & & \\
No. & name & Tree species & Treatment & Origin & Price $\left(\mathrm{NOK} / \mathrm{m}^{2}\right)$ \\
\hline I & Ipé & Tabebuia spp. & Untreated tropical hardwood & Brazil & 620 \\
II & TMF & Pinus silvestris & Pressure treatment, organic biocides & Norway & 136 \\
III & Kebony & Pinus silvestris & Pressure treatment and curing, furfuryl alcohol & Norway & 150 \\
IV & Russian larch & Larix sibirica & Untreated heartwood from larch & Russia & 208 \\
V & Wolmanit & Pinus silvestris & Pressure treatment, copper & Norway & 93 \\
\hline
\end{tabular}

bebuia spp.), (II) pressure-treated Scots pine (Pinus silvestris L.) (organic biocides), (III) modified Scots pine (furfurylation), (IV) naturally decay-resistant heartwood from Russian larch (Larix sibrica Ledeb.), and (V) pressure-treated Scots pine (copper and boron). Deck materials II and V are traditional pressure treatments with active agents inhibiting biological decay. Deck materials I and IV are naturally decayresistant wood. Deck material III is modified wood. Information about the five deck materials is provided in Table 1.

The material samples presented to the sensory profilers and the customers were made to look like traditional home decks. These sample decks were rectangular, measuring $1000 \mathrm{~mm} \times 625 \mathrm{~mm}$ and consisted of six parallel boards, each measuring $1000 \mathrm{~mm} \times 950 \mathrm{~mm} \times 28 \mathrm{~mm}$, fastened to two perpendicular boards on the underside of the deck, cf. Fig. 2. The boards were placed with the year rings facing up. To cover the possible variation in the appearance of the deck materials, four replicate samples of each deck material were made. Material was purchased from builders' merchants, but furfurylated wood was not commercially available and, therefore, was provided by the manufacturer.

\section{Sensory analysis}

Sensory analysis is a method for identification and measurement of product attributes perceived by sight, sound, smell, taste, and touch (Lawless and Heymann 1998). Sensory analysis has been used in food research for more than 50 years and has been used to study various nonfood products, for example, in the cosmetics industry (smell) and in telecommunications (sound). Sensory methods are classified according to their primary use; usually, a distinction is made between analytical methods with the purpose of providing objective descriptions of products (analytical sensory profiling) and hedonic methods where the purpose is to retrieve information about consumers' preferences and attitudes towards products (hedonic profiling) (Evin and Siekierski 2002).

Analytical sensory profiling is conducted by a panel consisting of assessors (judges) who are trained in defining, understanding, and evaluating product attributes. An analytical sensory panel usually consists of 10-20 trained persons (Evin and Siekierski 2002). Hedonic studies are usually carried out using 60-500 representative customers. In the product-development process, sensory profiling provides a complement to other sensory methods, such as market monitoring, consumer surveys, and focus groups, and to instrumental measurements. The analytical sensory study was carried out by a panel of nine well-trained assessors. All the assessors were previously screened for the ability to discriminate between samples with very small variations in intensity of given attributes . Prior to the analysis of the five product samples, the panel had been presented with 22 wood sam- ples representing various species and treatments. The panel agreed on 23 unambiguous sensory attributes that described visible variations in the surface of the samples. This list of attributes contained only generic terms (cf. International Standards Organization (ISO) 1993, 2003): words specific to tree species (for example, pine, larch, and oak) were avoided. The panel was then shown the five deck material samples to validate the sensory attributes; based on this presentation, five attributes were excluded from the analytical sensory study, for example, attributes related to the sensation of taste.

When the assessors had agreed on the 18 sensory attributes, an analytical sensory study was carried out on the sample decks shown in Fig. 2. (There were four replicates for each deck material.) Visual appearance of the deck materials was described by color, surface gloss, and natural pattern in the wood. Richness of the surface was measured by the assessors touching the sample decks by hand, and hardness was measured by the assessors walking on the sample decks. All samples were evaluated in a sensory laboratory under identical light conditions (ISO 1988). All members of the panel were allowed to evaluate the samples at individual speed and results were recorded on a $15 \mathrm{~cm}$ nonstructured scale. The left side of the nonstructured scale corresponded to the lowest intensity of each attribute (score $=1$ ), and the right side corresponded to the highest intensity ( score $=9$ ). No information was given to the assessors about deck material or purpose of the test. A list of the sensory attributes and their definitions is presented in Table 2.

The hedonic sensory study was carried out on a group of Norwegian potential consumers. The potential consumers were presented with the same material samples as the trained assessors (cf. Fig. 2) and stated their degrees of preference or acceptance towards the presented material sample by rating each sample deck on a scale from 1 (dislike very much) to 9 (like very much). Ninety-four respondents took part in the hedonic profiling: 63 females, 28 males, and 3 respondents who did not report gender. The age of the respondents ranged from 20 to 60 years. The respondents were researchers, research assistants, or administrative personnel working at the Norwegian Food Research Institute (MATFORSK). The customers had no specific knowledge of wood quality or residential deck materials. All samples were evaluated indoors under identical light conditions, and each respondent was allowed to evaluate the samples at individual speed. No information was given to the respondents about deck material or the purpose of the test. Compared with the population in the Oslo region, women and persons with higher education were overrepresented. Still, it is reason to believe that the results provide information about Norwegian consumers' preferences for wood attributes. 
Fig. 2. The five sample decks used in the study $(a)$ untreated ipé (Tabebuia spp.), (b) organic biocide treated Scots pine (Pinus sylvestris (L.), (c) furfuylated Scots pine, $(d)$ untreated Russian larch (Larix sibrica Ledeb.), and (e) copper-treated Scots pine).

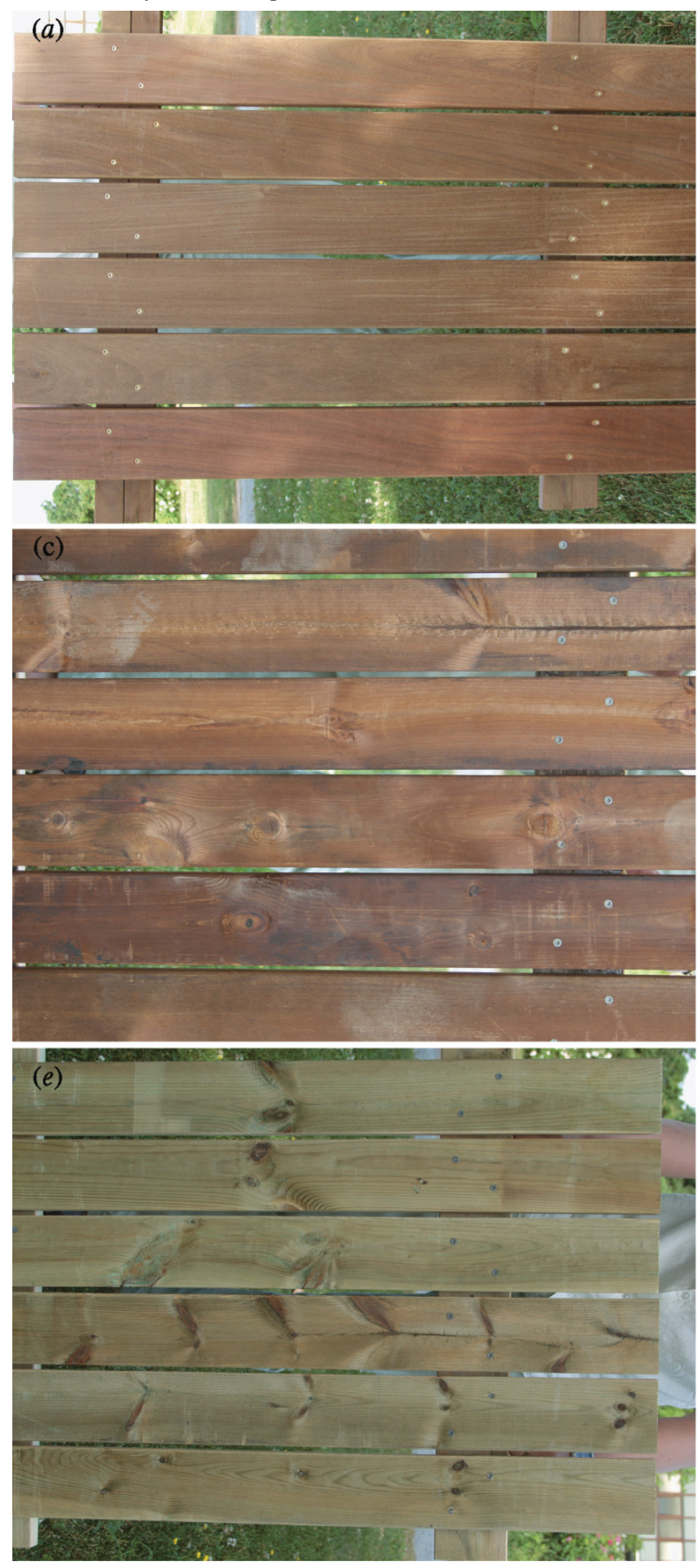

\section{Statistical analysis}

\section{Partial least-squares regression}

Partial least-squares regression (PLSR) was used to analyze the sensory data. It can be argued that multidimensional
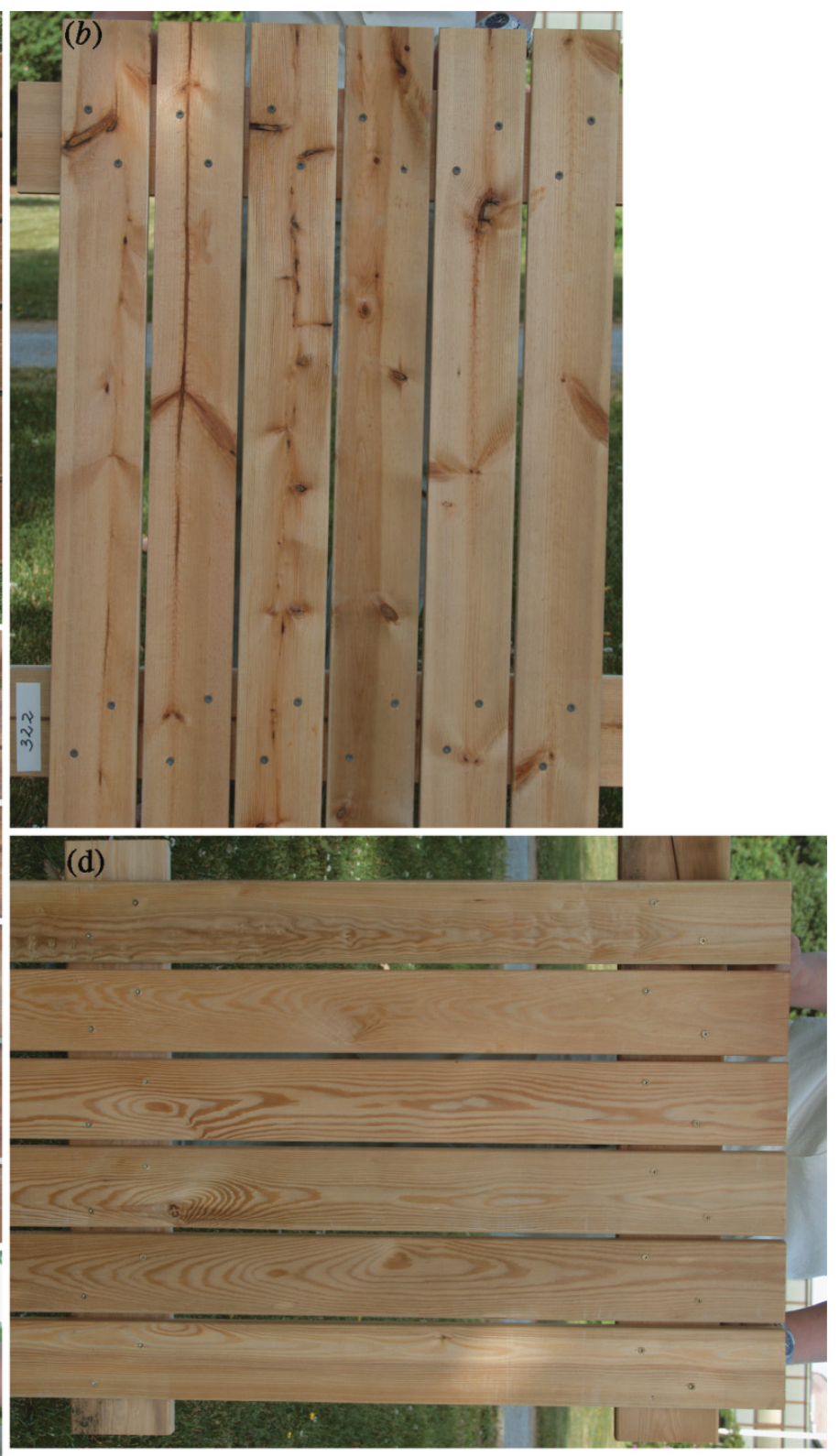

and multivariate analyses are useful statistical methods for interpreting systematic variation in one or more data matrices of sensory responses. The relationship between affective, hedonic data and analytical, descriptive data can be modeled by PLSR. The estimator is based on the transition of a large 
Table 2. Sensory attributes identified by the sensory panel and used to evaluate the five sample decks.

\begin{tabular}{llll}
\hline Sensory attribute & Definition & Score $=1$ & Score $=9$ \\
\hline Whiteness & Degree of white or black in the color & White & Black \\
Color hue & Green-yellow to yellow-red & Green-yellow & Yellow-red \\
Color intensity & Clear, strong color & Indistinct & Clear and strong \\
Color homogeneity & Color evenly spread on the surface & Uneven & Even \\
Growth ring & Growth rings evenly spread & Uneven & Even \\
Surplus color & Redundant color & Little & Much \\
Gloss & Shiny surface & Dull & Shiny \\
Knot size & Small or big knots & Small & Big \\
Knot shape & Round or oval knots & Round & Oval \\
Knot density & Few or many knots & Few & Many \\
Dry knots & Dry and shrinking knots & Negligible & Considerable \\
Knot pattern & Evenly spread knots on the surface & Homogenous pattern & Heterogeneous pattern \\
Fracture & Fracture due to dry branch mark & Negligible & Considerable \\
Rich surface & Feeling of richness when touching the surface & Dry & Rich \\
Growth ring homogeneity & Visual pattern formation of growth rings & Homogenous & Heterogeneous \\
Growth ring density & Dense growth ring patterns & Open & Dense \\
Hardness when walked on & Hard or soft feeling when walking on the surface without shoes & Soft feeling & Hard feeling \\
Smoothness & Feeling of smoothness when touching the surface & Rough surface & Smooth surface \\
\hline
\end{tabular}

number of original independent variables to a new set of variables made up from a small number of orthogonal components, or latent variables. A set of dependent variables is regressed on the latent variables and since the latent variables are orthogonal, multicollinearity is eliminated in the regression. PLSR handles all sample sizes and does not impose distributional assumptions on the data (Wold et al. 1984), and therefore, problems that occur due to skewed data, typically experienced when evaluating preference data, do not affect PLSR estimates. Multivariate data analysis has increasingly been applied in food research during the last decades, represented by numerous methods (Risvik 2001).

To determine the optimal set of components, components relevant for both the independent variables and the dependent variables were estimated. This was done through simultaneously decomposing the matrix of independent variables, $\mathbf{X}$, and dependent variables, $\mathbf{Y}$, maximizing covariance - providing a generalized principal component analysis. Finally, a regression was carried out where the orthogonal components of $\mathbf{X}$ are used to predict $\mathbf{Y}$. Thus, the regression was carried out on the minimal number of orthogonal components that could be used to predict the independent variables, $\mathbf{Y}$. For the special case where $\mathbf{Y}$ was a vector and the matrix $\mathbf{X}$ had full rank, the PLSR procedure was identical to an ordinary multiple regression. A description of the PLSR estimator for applications in the social sciences is provided in Abdi (2003).

\section{Tukey's pairwise comparison test}

To compare sensory and preference scores for the different decks, the Tukey's' honestly significant difference (HSD) all-pairwise comparisons test was used. An example of the Tukey's test used on sensory data is described by Lea et al. (1997). The Tukey HSD all-pairwise comparisons test allows for testing whether group means within larger samples are mutually statistically different, i.e., the null hypothesis $\left(H_{0}\right): \mu_{1}=\mu_{2}=, \ldots,=\mu_{n}$. For this purpose, a $t$ test is not appropriate because of multiple testing of a sample (type I errors), and therefore, the Tukey's' comparison test calculates a corrected $t$ value. The Tukey's multiple comparison test, like both the $t$ test and ANOVA, assumes that the data from the different groups come from populations where the observations have a normal distribution and the standard deviation is the same for each group.

\section{Results}

\section{Sensory study}

Attribute intensities for each deck material measured by the analytical sensory panel are reported in Table 3 and Fig. 3. Scores for all sensory attributes were compared using pairwise comparison tests (Table 3). Test results indicated that mean scores for the different deck materials (i.e., tree species and treatment) differed significantly, implying that the sensory attributes can be used to discriminate between the different materials. Attributes related to color varied between scores 1 and 8; attributes describing amount and shape of knots varied between scores 1 and 7; attributes describing growth ring pattern and density varied between scores 2 and 7; and attributes describing physical texture (richness, smoothness and hardness when walked on) varied between scores 3 and 7 .

\section{Preference study}

Descriptive statistics from the hedonic profiling are reported in Table 4 and Fig. 4. The sample decks made from untreated ipé and larch were given high mean scores, whereas the two samples made from pressure-treated wood (copper and organic biocides) were given low mean scores. According to the Tukey's pairwise comparison test, consumer acceptance for pressure-treated pine was significantly lower than for the remaining samples.

PLSR was performed using sensory attributes from the trained panel as $\mathbf{X}$ variables and sensory attributes from the consumers as responses ( $\mathbf{Y}$ variables). The results are reported in Table 5. Two latent vectors explained $85 \%$ of the variance of $\mathbf{X}$ and $63 \%$ of the variance of $\mathbf{Y}$, and this suggests that these two dimensions should be kept for the final 
Table 3. Mean attribute intensity measured in the analytical sensory profiling.

\begin{tabular}{llllll}
\hline Sensory attribute & Untreated ipé & Copper-treated pine & Untreated larch & Organic biocide treatment, pine & Furfurylated pine \\
\hline Whiteness & $2.47 \mathrm{c}$ & $5.22 \mathrm{~b}$ & $6.58 \mathrm{a}$ & $6.19 \mathrm{ab}$ & $1.84 \mathrm{c}$ \\
Color hue & $7.90 \mathrm{ab}$ & $1.54 \mathrm{~d}$ & $5.18 \mathrm{c}$ & $6.81 \mathrm{~b}$ & $8.39 \mathrm{a}$ \\
Color intensity & $4.26 \mathrm{ab}$ & $5.71 \mathrm{a}$ & $3.0 \mathrm{~b}$ & $3.98 \mathrm{~b}$ & $3.59 \mathrm{ab}$ \\
Color homogeneity & $7.03 \mathrm{a}$ & $3.42 \mathrm{c}$ & $6.97 \mathrm{a}$ & $5.71 \mathrm{ab}$ & $4.81 \mathrm{bc}$ \\
Growth ring & $7.56 \mathrm{a}$ & $2.74 \mathrm{~b}$ & $4.46 \mathrm{~b}$ & $4.16 \mathrm{~b}$ & $4.08 \mathrm{~b}$ \\
Surplus color & $1.30 \mathrm{~b}$ & $5.66 \mathrm{a}$ & $1.10 \mathrm{~b}$ & $2.34 \mathrm{~b}$ & $5.64 \mathrm{a}$ \\
Gloss & $2.20 \mathrm{~b}$ & $5.46 \mathrm{a}$ & $6.24 \mathrm{a}$ & $6.28 \mathrm{a}$ & $5.73 \mathrm{a}$ \\
Knot size & $1.67 \mathrm{c}$ & $7.22 \mathrm{a}$ & $1.69 \mathrm{c}$ & $5.54 \mathrm{~b}$ & $5.32 \mathrm{~b}$ \\
Knot shape & $2.06 \mathrm{c}$ & $7.53 \mathrm{a}$ & $1.42 \mathrm{c}$ & $6.39 \mathrm{ab}$ & $5.06 \mathrm{~b}$ \\
Knot density & $1.52 \mathrm{c}$ & $6.63 \mathrm{a}$ & $1.43 \mathrm{c}$ & $5.47 \mathrm{~b}$ & $5.52 \mathrm{~b}$ \\
Dry knots & $1.28 \mathrm{~d}$ & $6.14 \mathrm{a}$ & $1.69 \mathrm{~d}$ & $4.89 \mathrm{~b}$ & $3.10 \mathrm{c}$ \\
Knot pattern & $2.00 \mathrm{~b}$ & $6.30 \mathrm{a}$ & $2.24 \mathrm{~b}$ & $6.32 \mathrm{a}$ & $6.14 \mathrm{a}$ \\
Fracture & $1.69 \mathrm{~b}$ & $4.18 \mathrm{a}$ & $1.42 \mathrm{~b}$ & $2.70 \mathrm{ab}$ & $3.66 \mathrm{a}$ \\
Rich surface & $2.67 \mathrm{~b}$ & $4.46 \mathrm{a}$ & $3.88 \mathrm{ab}$ & $3.59 \mathrm{ab}$ & $4.56 \mathrm{a}$ \\
Growth ring homogeneity & $2.76 \mathrm{c}$ & $6.93 \mathrm{a}$ & $6.76 \mathrm{a}$ & $4.46 \mathrm{~b}$ & $4.73 \mathrm{~b}$ \\
Growth ring density & $7.09 \mathrm{a}$ & $4.80 \mathrm{~b}$ & $4.78 \mathrm{~b}$ & $5.93 \mathrm{ab}$ & $6.01 \mathrm{ab}$ \\
Hardness when walked on & $7.17 \mathrm{a}$ & $5.44 \mathrm{~b}$ & $5.62 \mathrm{~b}$ & $5.24 \mathrm{~b}$ & $6.00 \mathrm{~b}$ \\
Smoothness & $6.13 \mathrm{a}$ & $3.41 \mathrm{~b}$ & $3.12 \mathrm{~b}$ & $6.14 \mathrm{a}$ & $3.04 \mathrm{a}$ \\
No. of extreme values & 10 & 12 & 8 & 3 & 3 \\
\hline
\end{tabular}

Note: Values in a row with different letters are significantly different (Tukey's honestly significant difference (HSD) all-pairwise comparison test, $p<0.05$ ).

solution. The latent vectors are reported in Table 6. The first latent vector, $\boldsymbol{P C 1}$, has high values for ipé and Russian larch and low values for copper-treated pine. $P C 1$ represents the surface texture. The second latent vector, $\boldsymbol{P C} 2$, has its highest value for Russian larch and lowest value for furfurylated pine. $\boldsymbol{P C} 2$ represents color intensity.

Results from the PLSR are also plotted in Fig. 5. The two latent vectors $\boldsymbol{P C 1}$ and $\boldsymbol{P C} \boldsymbol{2}$ define a two-dimensional plane. In addition, correlation loadings for the $\mathbf{X}$ variables (predictors) are italicized in the figure and $\mathbf{Y}$ variables (dependent variables) are shown as asterisks. Item loadings for the predictors are reported in Table 7. Copper-treated pine is located in the upper left quadrant, close to the various attributes related to knots as well as the surface attributes rich surface and gloss. Ipé is located in the opposite quadrant close to the attributes hardness when walked on, growth rings, color hue, and growth ring density; it differs the most from copper-treated pine. Untreated larch is located in the upper right quadrant, implying high and positive loadings on both $\boldsymbol{P C 1}$ and $\boldsymbol{P C 2}$. Organic biocide treated pine is located close to the origin where $\boldsymbol{P C 1}$ and $\boldsymbol{P C 2}$ intersect. Furfurylated pine is located in the lower half of the diagram close to the center of $\boldsymbol{P C 1}$ and on the negative side of $\boldsymbol{P C 2}$.

Differences between the five deck materials can be ascribed both to treatment method (or lack of treatment) and to wood quality. Treatment will normally affect color and surface richness, whereas wood quality is represented through attributes such as knottiness (amount of knots, knot size, and share of dry knots), year ring patterns, and tactile properties (smoothness, rich surface, and hardness when walked on). Untreated ipé and untreated larch had high loadings on $\boldsymbol{P C 1}$, and copper-treated pine had negative loadings. There is reason to believe that $\boldsymbol{P C 1}$ is related to visual appearance: ipé and larch lacked knots, whereas the year rings were hardly visible on the samples from ipé and highly visible on the larch samples. The samples from copper-treated pine had more and bigger knots than other samples (fre- quently, the knots were dry), growth ring patterns were highly visible and uneven, and there were substantial amounts of surplus color around the knots. Untreated larch had the highest loadings on $\boldsymbol{P C}$. This was evidently due to the whiteness and growth ring homogeneity of the material: furfurylated pine and ipé had the lowest loadings on PC2, due to the rich, dark color of these deck materials.

Correlation loadings for customer rating (dependent variables) are represented by asterisks in Fig. 5; almost 90\% are located in the right half of the diagram (i.e., with positive values of $\boldsymbol{P C 1}$ ). This implies that most customers prefer deck materials with a homogenous texture and dislike visually disturbing elements such as knots, surplus color, and uneven growth ring patterns. When it comes to color intensity, $\boldsymbol{P C 2}$, there is substantial variation, and it is difficult to draw specific conclusions based on the results.

\section{Discussion}

The study demonstrates a successful application of sensory analysis on a wood product. Five wooden residential deck materials were analyzed. Firstly, an analytical sensory profiling was carried out, and a panel of trained assessors identified sensory parameters that were relevant for describing five different wooden residential deck materials. Then, a hedonic profiling was carried out, and a group of potential consumers successfully distinguished between the five different wooden deck materials and rated these according to relative preference.

Consumers preferred the samples made from untreated, naturally resistant wood and disliked the samples made from treated wood. Sensory attributes for wood from larch and ipé differed significantly from the other materials in several respects. Surface color was homogenous (color homogeneity), there were fewer fractures (fractures), there were few knots, and the knot pattern was homogenous (knot size, knot shape, knot density, dry knots, and knot pattern). 
Fig. 3. Attribute intensity measured in the analytical sensory profiling. Graphical representation for the five deck materials: $(a)$ untreated ipé (Tabebuia spp.), (b) organic biocide treated Scots pine (Pinus sylvestris (L.), (c) furfuylated Scots pine, (d) untreated Russian larch (Larix sibrica Ledeb.), and (e) copper-treated Scots pine).

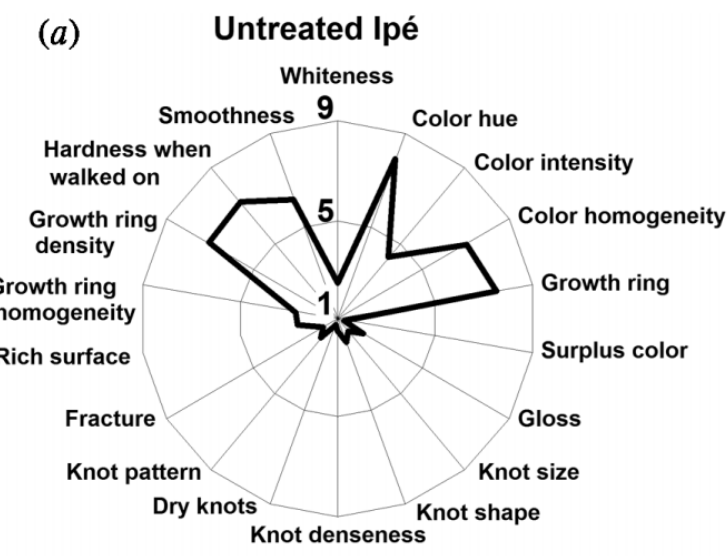

(c)

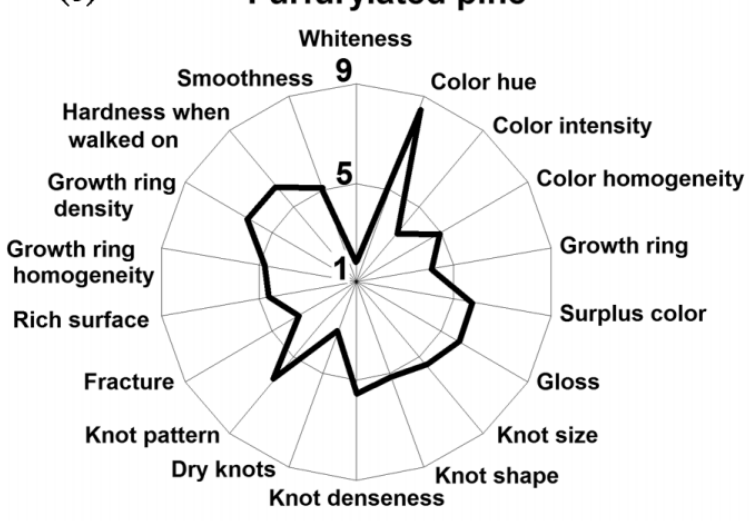

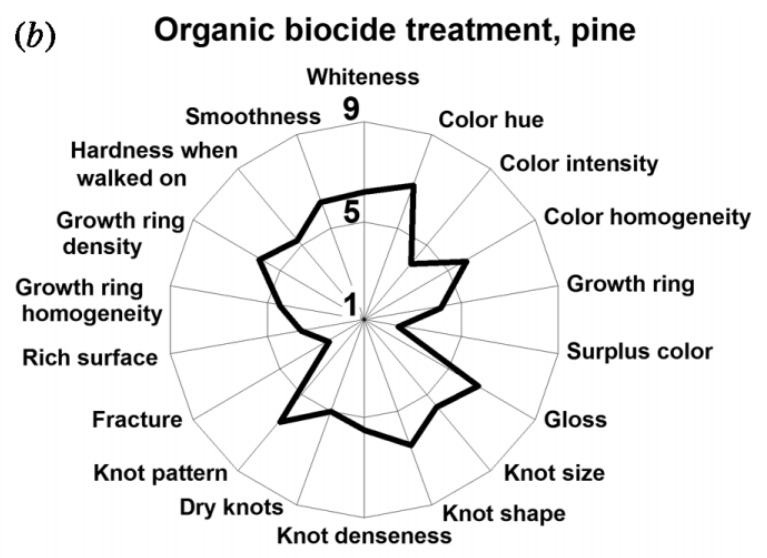

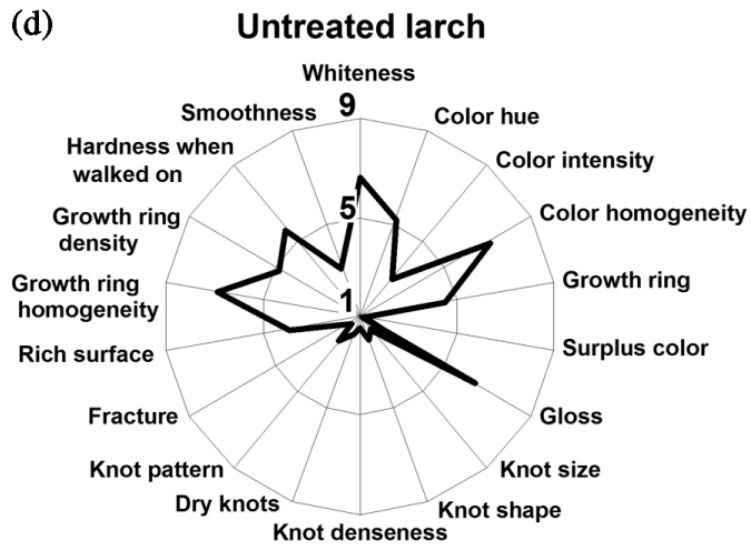

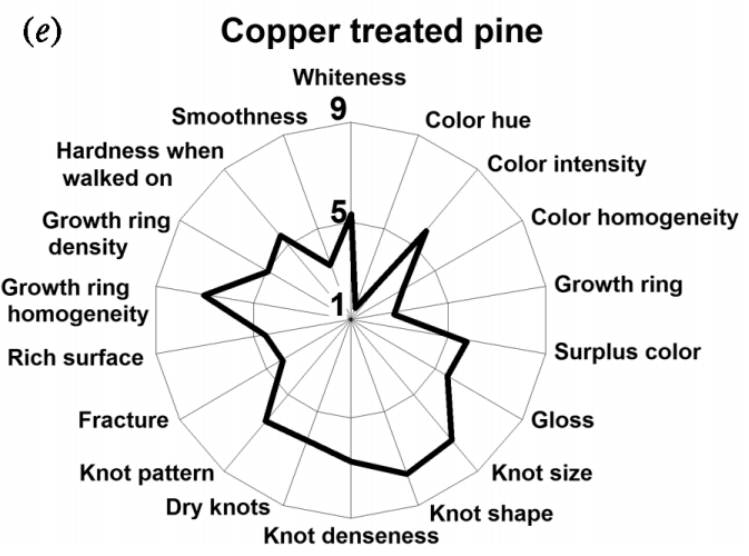

This implies that consumers prefer wood with homogenous visual surface characteristics and dislike wood with uneven surface characteristics. The treated wood was from pine of inferior quality, and the low-quality wood was evidently not appreciated by consumers.

The results from the sensory study were analyzed using PLSR. This indicated that the physical appearance of the material samples could be evaluated along two dimensions: surface texture (PC1) and color intensity (PC2). Surface texture relates to visual patterns on the wood surface; consumers apparently prefer wood with even colors and wood structure as well as an unstained appearance. The second most important product dimension, color intensity, relates to the appearance of the wooden surface as being neither too light, nor too dark/red. This result is probably equivalent to the conclusions reached by Bigsby et al. (2005), who suggested that key timber attributes are color and grain, as well as the results reached by Broman (2000), who suggested that consumers' preference for visual wood depended on texture activity and harmony. Texture activity and harmony most probably correspond to surface texture homogeneity as explained above. However, in contrast to the normative con- 
Table 4. Consumer preference measured in the hedonic profiling.

\begin{tabular}{llll}
\hline Type of wood & Mean score*,† & Median score* & No. of maximum scores \\
\hline Untreated ipé & $6.4 \mathrm{a}$ & 7 & 41 \\
Untreated larch & $5.9 \mathrm{ab}$ & 6 & 30 \\
Furfurylated pine & $5.2 \mathrm{~b}$ & 5 & 18 \\
Treated pine, organic biocides & $3.9 \mathrm{c}$ & 3 & 10 \\
Treated pine, copper & $3.8 \mathrm{c}$ & 3 & 5 \\
\hline *Nine-point Likert-type scale: 1, "do not like;" 9, "like very much." \\
†Values with different letters are significantly different. (Tukey's honestly significant difference (HSD) all-pairwise \\
comparison test.)
\end{tabular}

Fig. 4. Consumer preference measured in the hedonic profiling (nine-point Likert-type scale: 1, "do not like;" 9, "like very much").

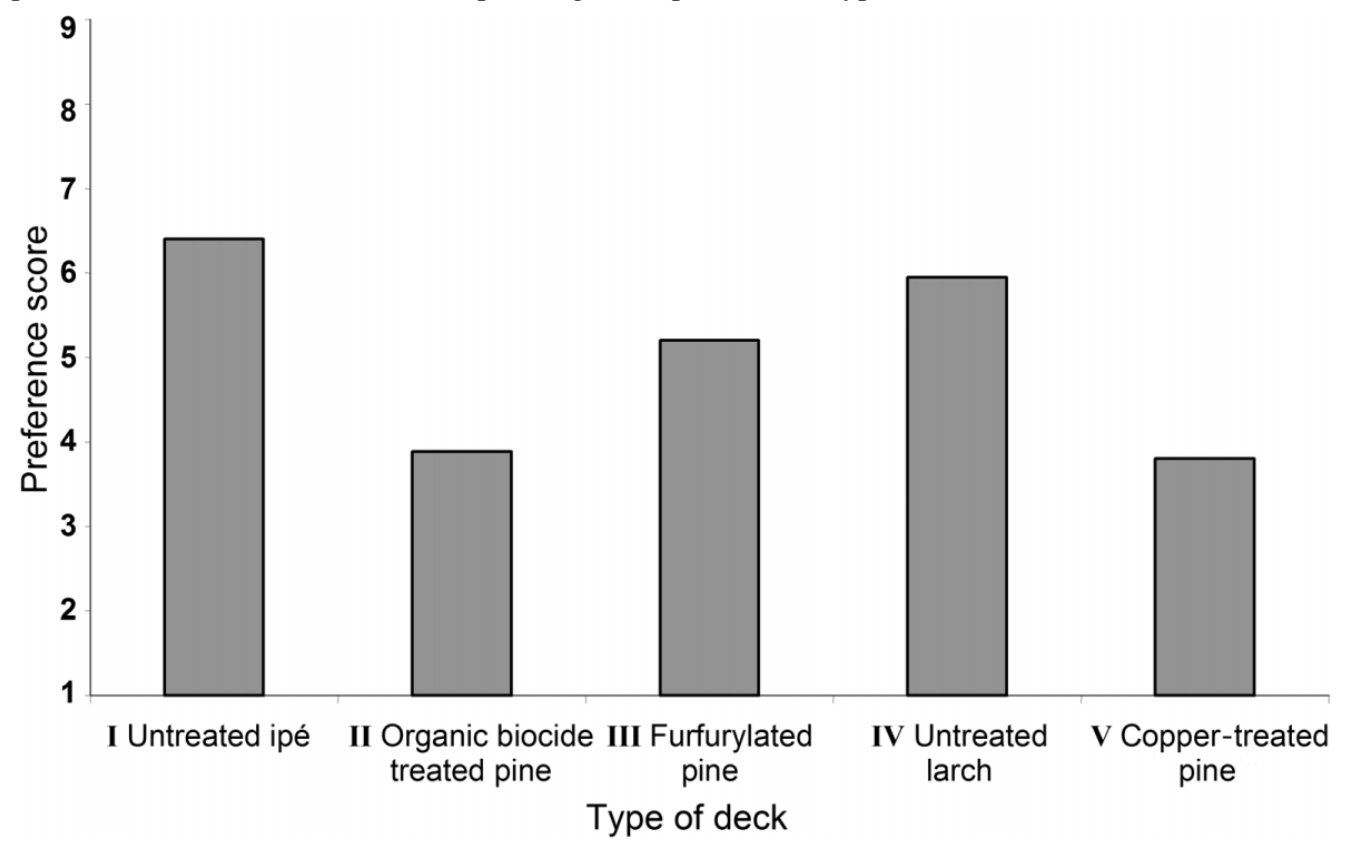

Table 5. Variance of $\mathbf{X}$ and $\mathbf{Y}$ described by the latent vectors.

\begin{tabular}{lll}
\hline Latent vectors & $\begin{array}{l}\text { Explained variance } \\
\text { for } \mathbf{X}(\%)\end{array}$ & $\begin{array}{l}\text { Explained variance } \\
\text { for } \mathbf{Y}(\%)\end{array}$ \\
\hline $\boldsymbol{P C 1}$ & 64 & 38 \\
$\boldsymbol{P C 2}$ & 21 & 25 \\
Total & 85 & 63 \\
\hline
\end{tabular}

Table 6. Latent vectors.

\begin{tabular}{lcr}
\hline & \multicolumn{2}{l}{ Latent vectors } \\
\cline { 2 - 3 } Type of wood & $\boldsymbol{P C 1}$ & \multicolumn{1}{c}{$\boldsymbol{P C 2}$} \\
\hline Untreated ipé & 0.708 & -0.397 \\
Untreated larch & 0.381 & 0.826 \\
Furfuyrlated pine & -0.123 & -0.625 \\
Treated pine, organic biocides & -0.236 & 0.007 \\
Treated pine, copper & -0.730 & 0.129 \\
\hline
\end{tabular}

cepts used by Broman (2000), the dimensions described in this study can be measured objectively by an analytical sensory panel.

The PLSR results imply that untreated larch and ipé exhibit attributes that make these preferred by the majority of consumers. According to the preference map in Fig. 5, most consumers prefer homogenous surfaces, represented by the horizontal dimension (PC1) and, therefore, are clustered in the right half of the diagram. There is less uniformity regarding the color intensity (PC2), but the center of the distribution is close to the center of the vertical axis, indicating that consumers prefer moderate color intensity. There are, however, no products located in this part of the diagram (right side of $\boldsymbol{P C 1}$ and center of $\boldsymbol{P C 2}$ ), and the majority of consumers would apparently prefer a type of deck material that differs from the material samples used in this study. According to these results, product developers should provide wooden deck materials that exhibit a homogenous surface texture and moderate color intensity.

The results displayed in the preference map are based on the actual sample decks that the sensory panel and consumers evaluated. As discussed above, the sample decks from pine were of inferior quality compared with the decks from larch and ipé. In particular, the sensory properties related to knots differed substantially (cf. Fig. 3). Inferior wood quality is probably an important reason why organic biocideand copper-treated pine was not preferred by the consumers. Because the evaluation carried out by consumers and sensory panel depends heavily on the material samples used in the study, therefore, the method may have limitations with respect to ranking consumer preferences for wood products. 
Fig. 5. Preference map. Projection of deck materials (boldface) on the first two latent vectors. Correlation loadings are italicized for the sensory attributes and are shown with asterisks for consumer responses. $\boldsymbol{P C 1}$, latent vector for surface texture; and $\boldsymbol{P C 2}$, latent vector for color intensity.

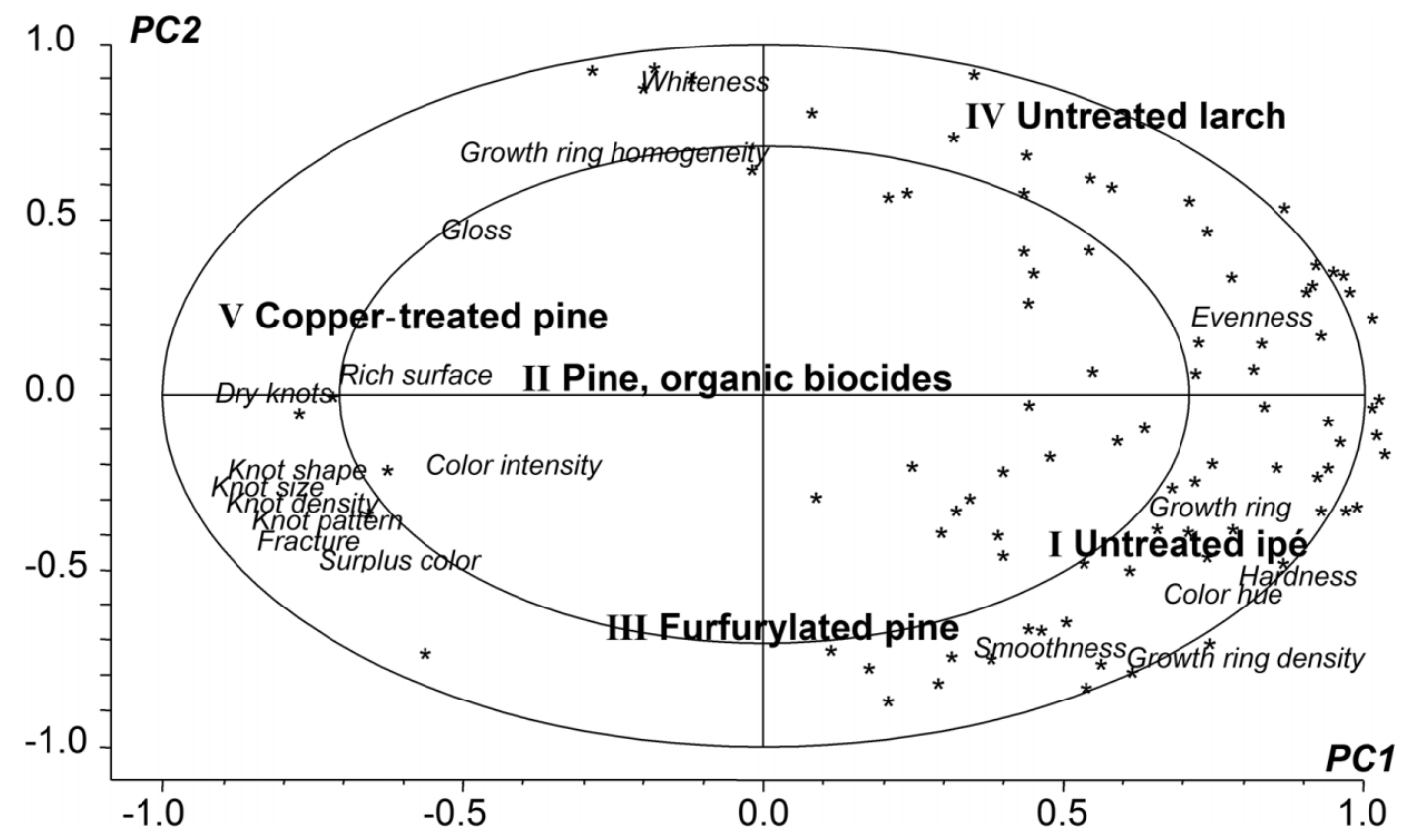

Table 7. Item loadings for sensory attributes.

\begin{tabular}{lrr}
\hline & \multicolumn{2}{c}{ Latent vectors } \\
\cline { 2 - 3 } Attribute & \multicolumn{1}{c}{$\boldsymbol{P C 1}$} & \multicolumn{1}{c}{$\boldsymbol{P C 2}$} \\
\hline Whiteness & -0.256 & 0.903 \\
Color hue & 0.616 & -0.558 \\
Color intensity & -0.613 & -0.790 \\
Color homogeneity & 0.937 & 0.229 \\
Growth ring & 0.895 & -0.310 \\
Surplus color & -0.792 & -0.440 \\
Gloss & -0.588 & 0.479 \\
Knot size & -0.970 & -0.231 \\
Knot shape & -0.943 & -0.236 \\
Knot density & -0.946 & -0.301 \\
Dry knots & -0.962 & 0.015 \\
Knot pattern & -0.903 & -0.305 \\
Fracture & -0.894 & -0.396 \\
Rich surface & -0.758 & 0.065 \\
Growth ring homogeneity & -0.556 & 0.700 \\
Growth ring density & 0.555 & -0.743 \\
Hardness when walked on & 0.743 & -0.526 \\
Smoothness & 0.300 & -0.667 \\
\hline
\end{tabular}

The method is particularly useful to identify salient product attributes that affect consumer preference.

Mean preference did not differ substantially between female and male respondents, and therefore, this result is not reported in the Results. This result contradicts the findings of Marchal and Mothe (1994), who found that preferences for oak wood was influenced by gender, among other factors. Close inspection of the consumer responses $(*)$ in the preference map in Fig. 5 revealed a slight difference between genders - females were inclined to favor colors that were slightly lighter than those preferred by the male respondents.
The assessors on the analytical sensory panel had no previous experience working with wood products. They had previously worked with describing the visual appearance and taste of food products. In spite of the lack of experience, the assessors had no problems identifying and measuring sensory attributes for the five different wood materials. Even though the attributes used in this study provided sufficient information to discriminate between the analyzed products, future analyses should probably focus on developing a set of generic attributes that relates to all kinds of wood products. For example, it would be a great advantage to develop a set of sensory attributes that relate to wood properties used in the wood science and the wood processing industries (e.g., density, knottiness, or fiber properties).

Results from the present study are useful and relevant for sawmills and the wood industry. Therefore, similar studies should be conducted on other types of wood products where visual and tactile wood attributes influence the consumers' purchasing decision. The impact of contextual information on consumer preferences is another issue worth focusing on; it is likely that consumer preference is influenced by usage context. For example, Jonsson (2005) found that consumers' choice of flooring material varied according to the type of room the flooring was intended for (e.g., wooden floors were preferred in the living room but not in the bathroom). Analyses focusing on treated wood products should explore other aspects of consumer behavior, for example, methods revealing consumers' willingness to pay for different product attributes. Studies comparing consumers from different geographical regions are also needed to determine whether the results presented above are influenced by culture.

\section{References}

Abdi, H. 2003. Partial least squares (PLS) regression. In Encyclopedia of social sciences research methods. Edited by M.S. Lewis- 
Beck, A. Bryman, and T. Futinq Liao. Sage Publishing, Thousand Oaks, Calif. pp. 792-795.

Ajzen, I., and Fishbein, M. 1977. Attitude-behavior relations: a theoretical analysis and review of empirical research. Psychol. Bull. 84: 888-918. doi:10.1037/0033-2909.84.5.888.

Ajzen, I., and Fishbein, M. 1980. Understanding attitudes and predicting social behavior. Prentice-Hall, Englewood Cliffs, N.J.

Australian Pesticides and Veterinary Medicines Authority. 2005a. The reconsideration of registrations of arsenic timber treatment products (CCA and arsenic trioxide) and their associated labels: report of review findings and regulatory outcomes. Summary report, March 2005. Australian Pesticides and Veterinary Medicines Authority, Symonston, ACT, Australia.

Australian Pesticides and Veterinary Medicines Authority. $2005 b$. Some uses of CCA timber treatments to be phased out [online]. Australian Pesticides and Veterinary Medicines Authority, Symonston, ACT, Australia. Available from www.apvma.gov.au/ media/mr0501.shtml [accessed 2 May 2007].

Bigsby, H., Rai, C., and Ozanne, L. 2005. Determining consumer preference for furniture timber [serial online]. J. For. Prod. Bus. Res. 2(2). Available from www.forprod.org/jfpbr.html [accessed 2 May 2007].

Brandt, J.P., and Shook, S.R. 2005. Attribute elicitation: implications in the research context. Wood Fiber Sci. 37: 127-146.

Broman, N.O. 2000. Means to measure the aesthetic properties of wood. Ph.D. thesis, Luleå University of Technology, Luleå, Sweden.

Donovan, G., and Hesseln, H. 2004. Consumer willingness to pay for naturally decay-resistant wood products. West. J. Appl. For. 19: $160-164$.

Engel, J.F., Blackwell, R.D., and Miniard, P.W. 1995. Consumer behavior. Dryden Press, Fort Worth, Texas.

European Commission. 2003. Commission Directive 2003/2/EC of 6 January 2003 relating to restrictions on the marketing and use of arsenic (tenth adaptation to technical progress to Council Directive 76/769/EEC). Vol. 4. European Commission, Brussels. pp. 9-11.

Evans, R., and Smith, N. 1968. Exploratory study in consumer behavior. For. Prod. J. 18: 15-18.

Evin, F., and Siekierski, E. 2002. Sensory evaluation of heating and air conditioning systems. Energy Buildings, 34: 647-651. doi:10.1016/S0378-7788(02)00015-4.

Fell, D.R., Thomas, J., and Hansen, E. 2006. Evolving consumer preferences for residential decking materials. For. Chron. 82: 253-258.

Fishbein, M. 1963. An investigation of the relationships between beliefs about an object and the attitude towards that object. Hum. Relat. 16: 233-240. doi:10.1177/001872676301600302.

Goldstein, I.S., Jeroski, E.B., Lund, A.E., Nielson, J.F., and Weater, J.M. 1969. Acetylation of wood in lumber thickness. For. Prod. J. 1: 363-370.

International Standards Organzation (ISO). 1988. ISO standard 8589: sensory analysis - general guidance for the design of test rooms. International Standards Organzation, Geneva.

International Standards Organzation (ISO). 1993. ISO standard 8586-1: sensory analysis - general guidance for the selection, training and monitoring of assessors. Part 1. Selected assessors. International Standards Organzation, Geneva.

International Standards Organzation (ISO). 2003. ISO standard 13299: Sensory analysis - methodology — general guidance for establishing a sensory profile. International Standards Organzation, Geneva.

Jacobsen, B., and Evans, F. 2002. Surface treatment of wood for outdoor use. Norsk Treteknisk Institutt, Oslo. NTI Tekniske småskrift. Del 1. [In Norwegian.]

Jonsson, R. 2005. Studies in the competitiveness of wood-market segmentation and customer assessment. Ph.D. thesis, Växjö University, Växjö, Sweden.

Lancaster, K. 1966. A new approach to consumer theory. J. Polit. Econ. 74: 132-156. doi:10.1086/259131.

Lande, S., Eikenes, M., and Westin, M. 2004. Chemistry and ecotoxicology of furfurylated wood. Scand. J. For. Res. 19: 283288.

Lawless, H., and Heymann, H. 1998. Sensory evaluation of food: principles and practices. Chapman \& Hall, New York.

Lea, P., Næs, T., and Rødbotten, M. 1997. Analysis of variance for sensory data. John Wiley \& Sons Ltd., London.

Lebow, S., Foster, D., and Lebow, P. 2004. Rate of CCA leaching from commercially treated decking. For. Prod. J. 54: 81-88.

Marchal, R., and Mothe, F. 1994. Appreciation of oak wood for the French consumer and wood professionals. Ann. Sci. For. 51: 213-232. doi:10.1051/forest:19940302.

Office of the Federal Register. 2003. Response to requests to cancel certain chromated copper arsenate (CCA) wood preservative products and amendments to terminate certain uses of other CCA products. US National Archives and Records Administration, Office of the Federal Register, College Park, Md. Federal Register 68. pp. 17366-17372.

Pachauri, M. 2001. Consumer behaviour: a literature review. Market. Rev. 2: 319-355. doi:10.1360/1469347012569896.

Pakarinen, T., and Asikainen, A. 2001. Consumer segments for wooden household furniture. Holz Roh Werk. 59: 217-227. doi:10.1007/s001070100187.

Reddy, V., and Bush, R. 1998. Measuring softwood lumber value: a conjoint analysis approach. For. Sci. 44: 145-157.

Risvik, E. 2001. The food and I. Sensory perception as revealed by multivariate methods. In Food, people and society: a European perspective of consumers' food choices. Edited by L. Frewer, E. Risvik, and H. Schifferstein. Springer-Verlag, Heidelberg, Germany. pp. 23-37.

Ryan, M. 1986. Implications from the "old" and the "new" physics for studying buyer behavior. In Perspectives on methodology in consumer research. Edited by D. Brinberg and R. Lutz. Springer-Verlag, Berlin. pp. 37-63.

Shook, S.R., and Eastin, I.L. 2001. A characterization of the US residential deck material market. For. Prod. J. 51: 28-36.

Smith, P.M., and Sinclair, S.A. 1989. The do-it-yourself customer for CCA-treated lumber products. For. Prod. J. 39: 35-41.

Smith, P.M., and Sinclair, S.A. 1990. The professional contractor/ remodeler: market research for CCA-treated lumber products. For. Prod. J. 40: 8-14.

Timber Decking Association. 2005. TDA anticipates further growth in UK decking market in 2005 [online]. Available from www.tda. org.uk/NetBuildPro/process/23/newsview6.html [accessed 2 May 2007].

Townsend, T., Solo-gabriele, H., Tolaymat, T., Stook, K., and Hosein, N. 2003. Chromium, copper, and arsenic concentrations in soil underneath CCA-treated wood structures. Soil Sediment Contam. 12: 779-798. doi:10.1080/714037715.

United Kingdom Forestry Commission. 2004. UK timber market statement - September 2004 [online]. United Nations Economic Commission for Europe Timber Committee, Geneva. Available from www.unece.org/trade/timber/mis/market/market-62/ unitedkingdom.pdf [accessed 2 May 2007].

United Kingdom Forestry Commission. 2005. UK timber market statement - September 2005 [online]. United Nations Economic Commission for Europe Timber Committee, Geneva. Available 
from www.unece.org/trade/timber/mis/market/market-63/ united\%20kingdom.pdf [accessed 2 May 2007].

United States Environmental Protection Agency. 2005. Chromated copper arsenate (CCA): timeline of major CCA actions. United States Environmental Protection Agency, Washington, D.C.

Vlosky, R.P., and Shupe, T.F. 2002. Homeowner attitudes and preferences for building materials with an emphasis on treated wood products. For. Prod. J. 52: 90-95.

Vlosky, R.P., and Shupe, T. 2004. US homebuilder perceptions about treated wood. For. Prod. J. 54: 41-48.

Vlosky, R.P., and Shupe, T. 2005. Manufacturers' perceptions about using treated wood in children's playground equipment. For. Prod. J. 55: 191-193.

Western European Institute for Wood Preservation. 2006. The wood preservation industry [online]. Western European Institute for Wood Preservation, Brussels. Available from www.wei-ieo. org/headframe.htm [accessed 2 May 2007].

Wold, S., Ruhe, A., Wold, H., and Dunn, W.J., III. 1984. The collinearity problem in linear regression. The partial least squares (PLS) approach to generalized inverses. SIAM J. Sci. Comput. 5: 735-743. doi:10.1137/0905052. 